\title{
ДРУГИЕ ГРАНИ
}

\section{МИТОХОНДРИАЛЬНОГО АНТИОКСИДАНТА В ОФТАЛЬМОЛОГИИ}

\begin{abstract}
Роль окислительного стресса в развитии и прогрессировании возраст-обусловленных заболеваний в офтальмологии достаточно изучена и доказана. Однако применение именно митохондриального антиоксиданта при данных патологиях изучено недостаточно.
\end{abstract}

Цель: исследовать эффективность глазных капель Визомитин ${ }^{\circledR}$ при возрастной катаракте и их влияние на параметры гидродинамики глаза.

Материалы и методы. Проведено исследование 2-х групп пациентов (возраст - 63,8 \pm 4,3 года). Пациенты группы I с возрастной катарактой в начальной стадии получали Визомитин ${ }^{\circledR}$ по 1-2 капле 3 р/сут, группы II - инстилляции гипромеллозы. Результаты. Через 4 мес. лечения достоверные (р < 0,05) изменения остроты зрения (03) составили 0,1 в группе I и 0,05 В группе II. У пациентов, применявших препарат Визомитин ${ }^{\circledR}$, после 1-го мес. и через 4 мес. применения наблюдалась небольшая тенденция к повышению уровня внутриглазного давления (ВГД). Также у пациентов группы I коэффициент легкости оттока при первичном обследовании составил 0,28 \pm 0,01 и недостоверно снизился при повторном обследовании через 1 мес. до 0,25 ะ 0,01. Минутный объем камерной влаги у больных группы I при первичном обследовании соста-

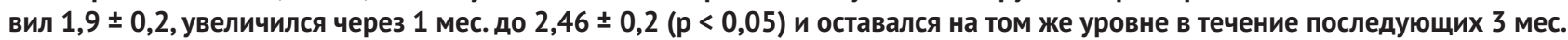
Заключение. Назначение препарата Визомитин ${ }^{\circledR}$ пациентам с начальной стадией катаракты приводит к положительному терапевтическому эффекту (повышению ОЗ). У пациентов, применявших препарат Визомитин ${ }^{\circledR}$, значимо изменяются гидродинамические показатели. Через 1 мес. применения увеличивается продукция внутриглазной жидкости (ВГж), через 4 мес. - ее отток.

Ключевые слова: возрастная катаракта, электротонография, митохондриальный антиоксидант, Визомитин.

\section{I.R. GAZIZOVA, MD,}

\section{OTHER FACETS OF MITOCHONDRIAL ANTIOXIDANT IN OPHTHALMOLOGY}

The role of oxidative stress in the development and progression of age-related diseases in ophthalmology sufficiently studied and proven. However application mitohondrail antioxidant is not enough studied under these pathologies.

Objective: To investigate the clinical efficacy Vizomitin with age-related cataract and its influence on the parameters of hydrodynamics eyes.

Materials and methods. A clinical study of 2 groups of patients (age 63,8 $\pm 4,3$ years). One group - with age-related cataract in the initial stage, which was appointed Vizomitin ${ }^{\circledR}$ 1-2 drops 3 times a day. Patients of the second group received instillation hypromellose. Results. After 4 months of treatment, the difference in the visual acuity in the study group became true and was 0.1 in podruppe I and 0.05 in the subgroup II ( $p<0.05$ relative to the same sub-groups at the beginning of treatment).

Patients with Vizomitin group after the first month and 4 months after the application was observed a slight tendency to increased intraocular pressure. Also, patients in group I ease the outflow coefficient during the initial survey was $0,28 \pm 0,01$ and decreased during the second examination after 1 month to 0,25 $\pm 0,01$ difference was not significant. Minute volume of chamber moisture in group I patients at initial assessment was $1,9 \pm 0,2$ and increased after 1 month to $2,46 \pm 0,2(p<0.05)$ and remained the same over the next 3 months.

Conclusion. Appointment Vizomitin in patients with an initial stage of cataract leads to a positive therapeutic effect (increase in visual acuity). Patients who used Vizomitin significantly change the hydrodynamic performance. After a month of application is increased production of intraocular fluid and increases its outflow in 4 months.

Keywords: mitochondrial antioxidant Vizomitin, senile cataract, elektrotonografiya.

ак известно, спектр действия антиоксидантов весьма разнообразен и обусловлен в основном способностью нейтрализовать негативное действие свободных радикалов. В мире используется свыше трех десятков соединений различных групп. Однако в России доступны лишь некоторые препараты: эмоксипин, мексидол (мексифин), гистохром, полиоксидоний, офтан-катахром, антоциан форте, стрикс. В настоящее время доказана высокая результативность их применения [10, 13].

Влияние антиоксидантов на человека широко обсуждается в научных кругах. Особое место в этой дискуссии занимает препарат Визомитин ${ }^{\circledR}$, действующим веществом которого является митохондриальный антиоксидант пластохинонилдецилтрифенилфосфония бромид (ПДТФ) (научное название - SkQ1) в концентрации 155 нг/мл [6, 7].
Препарат Визомитин ${ }^{\circledR}$ в короткие сроки уменьшает частоту жалоб и устраняет клинические симптомы синдрома «сухого глаза» (ССГ), способствует стабилизации слезной пленки, эпителизации роговицы [5]. Данный препарат рекомендован к широкому применению для лечения роговично-конъюнктивального ксероза при офтальмопатологии различной этиологии. Однако диапазон лечебного воздействия антиоксидантов достаточно широк, постоянно проводятся новые исследования, которые позволяют определить показания и алгоритм их применения, открывают новые грани профилактики и лечения многих заболеваний глаз, особенно связанных с возрастной патологией.

Возрастная катаракта - самое распространенное заболевание среди пожилого населения, и роль окислительного стресса в развитии и прогрессировании данного 
заболевания достаточно изучена и доказана [12]. Особый интерес в этой связи представляет изучение применения митохондриального антиоксиданта при данной патологии. Клиническое исследование препарата Визомитин ${ }^{\circledR}$, проведенное у пациентов с начальной стадией возрастной катаракты, продемонстрировало эффективность ПДТФ для улучшения динамики остроты зрения (03) [14]. По результатам исследования препарат Визомитин ${ }^{\circledR}$ разрешен к применению по данному показанию.

Как известно, глаукома также является возраст-обусловленным заболеванием, и снижение антиоксидантной защиты - одно из важных звеньев патогенеза прогрессирования глаукомы [1]. Доказано, что митохондриальная дисфункция является одним из пусковых механизмов развития апоптоза клеток не только в ганглионарных волокнах сетчатки и зрительного нерва, но и в клетках трабекулярной зоны. В связи с этим особый интерес представляет изучение влияния митохондриального антиоксиданта на функции систем радужно-роговичного угла и цилиарного тела [2-4].

Цель: исследовать эффективность препарата Визомитин ${ }^{\circledR}$ при возрастной катаракте и его влияние на параметры гидродинамики глаза.

\section{МАТЕРИАЛЫ И МЕТОДЫ}

Проведено исследование двух групп пациентов (возраст - 63,8 \pm 4,3 года). В группу I были включены пациенты с возрастной катарактой в начальной стадии (27 человек - 42 глаза), которым был назначен препарат Визомитин ${ }^{\circledR}$ по 1-2 капле 3 р/сут в каждый глаз в течение 4 мес. Пациентов с незрелой катарактой не включали в исследование, поскольку они предпочитали хирургическое лечение. В группу II были включены пациенты, сопоставимые по возрасту с пациентами группы І, также с диагнозом «возрастная катаракта» (12 человек - 24 глаза), которым были назначены инстилляции гипромеллозы по 1-2 капле 3 р/сут в каждый глаз также в течение 4 мес. У пациентов обеих групп был также сопутствующий диагноз - ССГ. Критериями исключения были пациенты с любой другой офтальмологической патологией. Все пациенты прошли стандартное офтальмологическое обследование, дополнительно всем проводили электротонографию (ЭТГ). ОЗ оценивали по максимальным значениям с коррекцией. Контрольные исследования проводили через 1 и 4 мес. после назначения лечения. Статистическая обработка проводилась при помощи непараметрических методов исследования для зависимых групп. Коэффициент Стьюдента уровень значимости $p<0,05$. Данные описательной статистики представлены в виде $M \pm \sigma$ ( - среднее значение, $\sigma$ - стандартное отклонение).

\section{РЕЗУЛЬТАТЫ}

При первичном осмотре пациенты обеих групп предъявляли жалобы на затуманивание зрения, сухость в глазах, слезотечение на улице и чувствительность к внешним факторам. Через 4 мес. после лечения лишь у 1\% пациен- тов сохранялись жалобы на сухость и слезотечение, 14\% пациентов по-прежнему жаловались на затуманивание зрения, остальные пациенты отмечали улучшение состояния глазной поверхности и в меньшей степени предъявляли жалобы на затуманивание зрения.

При объективном осмотре передней глазной поверхности были выявлены клинические данные, представленные в таблице 1.

Таким образом, применение препарата Визомитин ${ }^{\circledR}$ по сравнению с препаратом, содержащим гипромеллозу, в большей степени нивелирует признаки проявления ССГ у возрастных пациентов с катарактой.

Из-за большого разброса клинических данных (стаж заболевания, О3 и офтальмоскопические признаки возрастной катаракты) при обработке данных группы пациентов были разделены подгруппы: группа I - на la и lb, группа II - на Ila и Ilb. При этом были учтены исходные значения максимальной корригированной 03. Соответственно, максимальная О3 в подгруппах la и Ila до начала наблюдения составляла от 0,85 до 0,6, а в подгруппах Ib и Ilb - от 0,55 до 0,3.

В таблище 2 представлены средние значения максимальной корригированной ОЗ в разные временные точки после начала применения препарата Визомитин ${ }^{\circledR}$ у пациентов с возрастной катарактой. Через 1 мес. после начала инстилляций ни в одной из групп достоверных различий показателей ОЗ замечено не было, хотя отмечалось некоторое повышение $\mathrm{O} 3$ по сравнению с исходными значениями, особенно в подгруппе la (пациенты с незначительными изменениями в хрусталике и изначально более высокой О3).

Однако после 4 мес. лечения разница в ОЗ в основной группе стала достоверной и составила 0,1 в подгруппе la и 0,05 в подгруппе lb (внутригрупповая достоверность p < 0,05). В контрольной группе прослеживалась лишь некоторая недостоверная тенденция к повышению 03. Наши результаты согласуются с проведенными ранее экспериментальными исследованиями, в которых был выявлен терапевтический потенциал SkQ1 - способность снижать выраженность патологических изменений или полностью нормализовать состояние хрусталиков крыс линии OXYS. Выраженность патологических изменений хрусталиков у крыс линии OXYS снизилась вдвое уже

\section{Таблица 1. Объективные клинические данные}

\begin{tabular}{|c|c|c|c|c|}
\hline $\begin{array}{l}\text { Объективные } \\
\text { признаки ССГ }\end{array}$ & \multicolumn{2}{|c|}{ До лечения, \% } & \multicolumn{2}{|c|}{$\begin{array}{c}\text { Через } 4 \text { мес. } \\
\text { после лечения, \% }\end{array}$} \\
\hline \multirow{2}{*}{ LIPCOF I-II } & Группа I & Группа II & Группа I & Группа II \\
\hline & 62 & 55 & 48 & 52 \\
\hline $\begin{array}{l}\text { «Вялая» гиперемия } \\
\text { конъюнктивы }\end{array}$ & 100 & 100 & 10 & 34 \\
\hline $\begin{array}{l}\text { Конъюнктивальное } \\
\text { отделяемое в виде } \\
\text { слизистых «нитей» }\end{array}$ & 24 & 15 & - & 1 \\
\hline $\begin{array}{l}\text { Участки прокрашивания } \\
\text { флуоресцеином }\end{array}$ & 43 & 47 & - & 23 \\
\hline
\end{tabular}


Таблица 2. Средние значения максимальной корригированной остроты зрения у пациентов с возрастной катарактой после лечения препаратом Визомитин ${ }^{\oplus}$

\begin{tabular}{|c|c|c|c|c|}
\hline \multirow{3}{*}{ Показатель } & \multicolumn{4}{|c|}{ Группы пациентов ( $=$ кол-во глаз) } \\
\hline & \multicolumn{2}{|c|}{$I(n=42)$} & \multicolumn{2}{|c|}{ II $(n=24)$} \\
\hline & la $(n=26)$ & $\mathrm{lb}(\mathrm{n}=16)$ & Ila $(n=14)$ & $\mathrm{Ilb}(n=10)$ \\
\hline \multicolumn{5}{|c|}{ До лечения } \\
\hline $\begin{array}{l}\text { Острота } \\
\text { зрения (ед.) }\end{array}$ & $0,71 \pm 0,04$ & $0,46 \pm 0,03$ & $0,62 \pm 0,15$ & $0,45 \pm 0,03$ \\
\hline \multicolumn{5}{|c|}{ Через 1 мес. после начала лечения } \\
\hline $\begin{array}{l}\text { Острота } \\
\text { зрения (ед.) }\end{array}$ & $0,73 \pm 0,03$ & $0,45 \pm 0,02$ & $0,61 \pm 0,06$ & $0,45 \pm 0,02$ \\
\hline \multicolumn{5}{|c|}{ Через 4 мес. после начала лечения } \\
\hline $\begin{array}{l}\text { Острота } \\
\text { зрения (ед.) }\end{array}$ & $0,82 \pm 0,03^{*}$ & $0,51 \pm 0,02^{*}$ & $0,65 \pm 0,04$ & $0,47 \pm 0,02$ \\
\hline
\end{tabular}

* - внутригрупповая достоверность $p<0,05$

через 1,5 мес. лечения и сохранялась на фоне терапии на одном уровне в течение 3,5 мес. Восприимчивыми к лечению SkQ1 оказались животные с начальными стадиями заболевания: у них наблюдалось стойкое улучшение состояния хрусталиков. У старых животных с развитой ядерной катарактой лечебный эффект отсутствовал $[9,11]$.

Таким образом, применение препарата Визомитин ${ }^{\circledR}$ у пациентов с начальной стадией катаракты, особенно с незначительными изменениями в хрусталике, с наиболее высокой ОЗ приводит к положительному терапевтическому эффекту - повышению 03.

Наиболее интересные данные получены при изучении результатов электротонографии. Поскольку в этом исследовании разброс значений ОЗ внутри групп не влиял на его результаты, сравнивали группу I и группу II. Результаты представлены в таблище 3.

Данные электротонографического исследования позволили оценить гидродинамические показатели в ходе использования глазных капель Визомитин ${ }^{\circledR}$. У пациентов группы I, применявших препарат Визомитин ${ }^{\circledR}$, наблюдалась небольшая тенденция к повышению уровня ВГД, в то время как в группе II уровень ВГД был стабилен.

Также у пациентов группы I коэффициент легкости оттока (С) при первичном обследовании составил 0,28 \pm 0,01 и недостоверно снизился при повторном обследовании через 1 мес. до 0,25 0 0,01. Через 4 мес. коэффициент легкости оттока увеличился даже по сравнению с началом лечения. У пациентов группы II он оставался стабильным весь период исследования.

Минутный объем камерной влаги (F) у больных группы I при первичном обследовании составил 1,9 \pm 0,2, увеличился через 1 мес. до 2,46 0 0,2 ( $<$ 0,05) и оставался на том же уровне в течение последующих 3 мес. Именно этим фактом объясняется незначительное повышение уровня ВГД у пациентов после 1 мес. применения препарата Визомитин ${ }^{\circledR}$. У больных группы II данный показатель также не изменялся.
Несмотря на колебания гидродинамических показателей, средняя величина коэффициента Беккера Ро/С в группах за весь период оставалась в пределах нормальных значений, что указывает на отсутствие патологических изменений гидродинамики глаза.

Факт изменения гидродинамических показателей в группе пациентов, применявших препарат Визомитин ${ }^{\circledR}$, нельзя оставить без комментариев. Это действие препарата, скорее всего, связано с его способностью увеличивать энергетический потенциал клеток, в данном случае - клеток цилиарного тела, увеличивая продукцию ВГЖ, с одной стороны, и ее отток через трабекулярную сеть - с другой. Этот эффект носит отсроченный, но стабильный характер. Возможно, именно усиление гидродинамических характеристик глаза и способствует усиленному питанию хрусталика и снижает прогрессирование возрастной катаракты.

Таким образом, у пациентов, применявших глазные капли Визомитин ${ }^{\circledR}$, значимо изменяются гидродинамические показатели. У пациентов с катарактой (без начальных изменений гидродинамических показателей) через 1 мес. применения препарата наблюдается увеличение продукции ВГЖ, а ее отток увеличивается через 4 мес. Однако нами не было проведено сравнение этих показателей у пациентов с нарушением гидродинамики.

Наше исследование носит пилотный характер и требует продолжения для более детального изучения данного явления. Необходимо увеличить выборку пациентов и длительность наблюдения. Особый интерес представляет исследование данных параметров у пациентов с первичной открытоугольной глаукомой.

\section{Таблица 3. Динамика электротонографических показателей в ходе применения препарата Визомитин ${ }^{\odot}$}

\begin{tabular}{|c|c|c|}
\hline \multirow{2}{*}{ Показатели } & \multicolumn{2}{|c|}{ Группы пациентов (n = кол-во глаз) } \\
\hline & I ( $n=42)$ & II $(n=24)$ \\
\hline \multicolumn{3}{|c|}{ До лечения } \\
\hline$P_{0}$ & $17,4 \pm 0,25$ & $17,8 \pm 0,21$ \\
\hline C & $0,28 \pm 0,01$ & $0,27 \pm 0,01$ \\
\hline $\mathrm{F}$ & $1,9 \pm 0,2$ & $1,55 \pm 0,2$ \\
\hline КБ & $62 \pm 6,2$ & $65,9 \pm 5,7$ \\
\hline \multicolumn{3}{|c|}{ Через 1 мес. после начала лечения } \\
\hline$P_{0}$ & $18,8 \pm 0,21$ & $17,6 \pm 0,26$ \\
\hline C & $0,25 \pm 0,01$ & $0,26 \pm 0,01$ \\
\hline $\mathrm{F}$ & $2,46 \pm 0,2^{*}$ & $1,61 \pm 0,2$ \\
\hline КБ & $75,2 \pm 6,6$ & $67,7 \pm 6,1$ \\
\hline \multicolumn{3}{|c|}{ Через 4 мес. после начала лечения } \\
\hline$P_{0}$ & $17,8 \pm 0,31$ & $17,8 \pm 0,21$ \\
\hline C & $0,32 \pm 0,01$ & $0,27 \pm 0,01$ \\
\hline $\mathrm{F}$ & $2,38 \pm 0,2^{*}$ & $1,57 \pm 0,2$ \\
\hline КБ & $55,6 \pm 7,4$ & $66 \pm 5,5$ \\
\hline
\end{tabular}

* - внутригрупповая достоверность $p<0,05$ 


\section{ЗАКЛЮЧЕНИЕ}

Применение препарата Визомитин ${ }^{\circledR}$ у возрастных пациентов с катарактой в большей степени нивелирует признаки проявления ССГ, чем применение препарата, содержащего только гипромеллозу.

Назначение препарата Визомитин ${ }^{\circledR}$ у пациентов с начальной стадией катаракты, особенно с незначительными изменениями в хрусталике, с наиболее высокой 03, приводит к положительному терапевтическому эффекту повышению 03.

У пациентов, применявших препарат Визомитин ${ }^{\circledR}$, изменяются гидродинамические показатели. У пациентов с катарактой (без начальных изменений гидродинамических показателей) через 1 мес. применения препарата наблюдается увеличение продукции ВГЖ, а ее отток увеличивается через 4 мес. Сравнение этих показателей у пациентов с нарушением гидродинамики проведено не было.

\section{ЛИТЕРАТУРА}

1. Абышева Л.Д., Авдеев Р.В., Александров А.С. и др. Оптимальные характеристики верхней границы офтальмотонуса у пациентов с развитой стадией первичной открытоугольной глаукомы с точки зрения доказательной медицины. РМЖ. Клиническая офтальмология, 2015, 16(3): 111-123.

2. Алексеев В.Н., Газизова И.Р., Никитин Д.Н. Структурные изменения митохондрий клеток трабекулярной зоны у больных первичной открытоугольной глаукомой. Современная оптометрия, 2012, 3: 18

3. Газизова И.Р. Митохондриальная патология и глаукома. Национальный журнал глаукома, 2012, 4: 58.

4. Газизова И.Р. Состояние окислительно-восстановительной системы у больных первичной открытоугольной глаукомой. Казанский медицинский журнал, 2012, 93(3): 488-490

5. Газизова И.Р., Тихомирова И.Ю. Клинические эффекты визомитина на поверхность глаза. Новости глаукомы, 2015, 1: 100-101.

6. Сенин И.И., Еричев В.П., Скулачев В.П. Митоинженерия в офтальмологии. Наука в России, 2011, 182(2): 4-12.

7. Яни Е.В., Катаргина Л.А., Чеснокова Н.Б., Безнос О.В., Савченко А.Ю. Выгодин В.А., Гудкова Е.Ю., Замятнин А.А., Скулачев М.В. Первый опыт использования препарата Визомитин в терапии «сухого глаза». Практическая медииина. Офтальмология, 2012, 4(1).

8. Mares JA. High-dose antioxidant supplementation and cataract risk Nutrition Reviews, 2004, 62(1): 28-32.

9. Rumyantseva YV, Ryabchikova El, Fursova AZ, Kolosova NG. Ameliorative effects of skq1 eye drops on cataractogenesis in senescence-accelerated OXYS rats. Graefe's Arch Clin Exper Ophthalmol, 2015, 253(2): 237-248.

10. Selin JZ, Rautiainen S, Lindblad BE, Morgenstern R, Wolk A. High-dose supplements of vitamins $C$ and $E$, low-dose multivitamins, and the risk of age-related cataract: a population-based prospective cohort study of men. Am J Epidemiol, 2013, 177(6): 548-555.

11. Snytnikova OA, Tsentalovich YP, Stefanova NA, Fursova AZ, Kaptein R, Sagdeev RZ et al. The therapeutic effect of mitochondria-targeted antioxidant skq1 and Cistanche deserticola is associated with increased levels of tryptophan and kynurenine in the rat lens. Doklady Biochemistry and Biophysics, 2012, 447(1): 300-303.

12. Sunkireddy P, Jha SN, Kanwar JR, Yadav SC. Natural antioxidant biomolecules promises future nanomedicine based therapy for cataract. Colloids Surf B: Biointerfaces, 2013, 112: 554-562.

13. Tomlinson A. Epidemiology of dry eye disease. In: Asbell P, Lemp MA, eds. Dry Eye Disease: The Clinician's Guide to Diagnosis and Treatment. New York: Thieme, 2006: 1-15.

14. Еричев В.П., Козлова И.В., Рещикова В.С., Алексеев В.Н., Левко М.А., Замятнин А.А., Гудкова Е.Ю., Ковалева Н.А., Выгодин В.А., Федоркин О.Н., Остапенко В., Сенин И.И., Савченко А.Ю., Попеко Н.А., Скулачев В.П., Скулачев М.В. Клиническое исследование эффективности и безопасности препарата Визомитин ${ }^{\circledR}$, глазные капли, у пациентов с возрастной катарактой. Национальный журнал глаукома, 2016: 15(1): 61-69.
Разработано в МГУ имени М.В.Ломоносова

\section{капли глазные}

\section{BИ30MИTИН}

Первый в мире зарегистрированный препарат адресной доставки в митохондрии,

предотвращающий окислительное повреждение клеток глаза.

Эффективное кератопротекторное средство,

достоверно ускоряет заживление роговицы

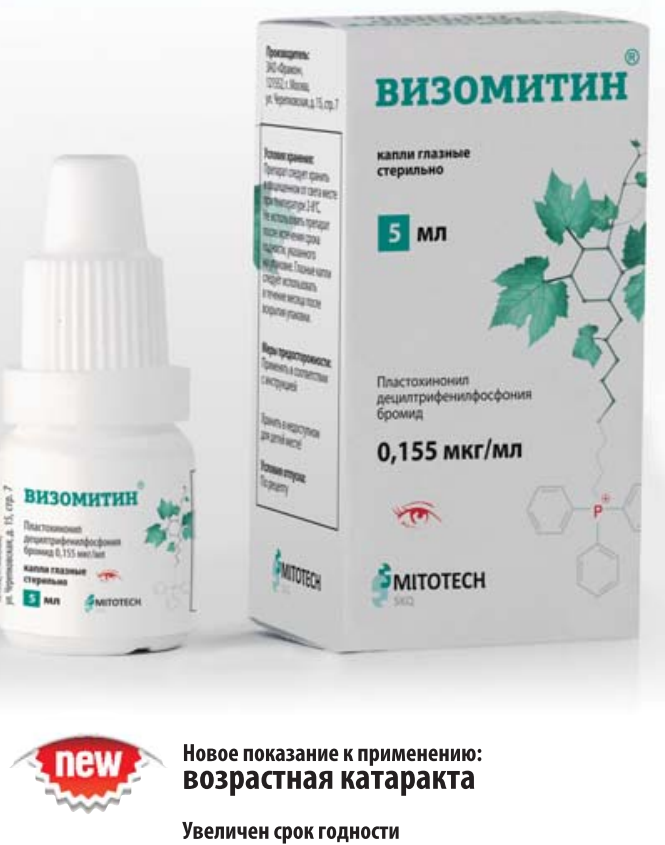

Оригинальный российский лекарственный препарат

Не имеет аналогов в мире

\section{Лекарственный препарат адресной доставки: подавляет окислительный стресс в месте его возникновения}

* Результаты клинических исследований глазных капель Визомитин ${ }^{\circledR}$ опубликованы в следующих статьях: Яни и соавт. (2012) Практическая медицина. 4 (59), стр. 134-137
Maксимова и соавт. (2014) Медицинский совет. 17, стр 16-19
Brzheskiy et al (2015) Advances in Therapy, 32 (12), pp 1263-1279
Petrov et al (2016) Advances in Therapy, 33 (1), pp 96-115 